\title{
Die Steinewerferin
}

Harriet Keller-Wossidlo

Korrespondenz:

Dr. med. Harriet Keller-Wossidlo Erlinsbacherstrasse 104

CH-5000 Aarau
Es war einmal ein Mädchen. Das wurde am Wasser geboren.

Schnell lernte es die Sprache der Wellen, ihr Lied, wenn die Wasser sich zurückzogen, und ihre Klagen, wenn das Wasser stieg.

Bei Sturm lernte sie die Zeichen der Wolken lesen und in der Sonne die Bewegungen der Schatten.

Gerne ging sie an den Wassern entlang: den Flüssen, den Meeren,

aber auch den Bächen und an den Säumen der Seen.

Und immer suchte sie etwas, oft fand sie auch etwas,

aber nicht das, was sie suchte ...

Dann eines Tages entdeckte sie eine graugrüne, mit Seegras bedeckte Muschel.

Erst wusste sie nicht so recht, was sie damit anfangen sollte:

sah die Muschel doch gar zu unansehnlich aus! Sie begann ganz vorsichtig die hässlichen Schichten abzutragen.

Dazu benötigte sie viel Zeit und grosse Sorgfalt.

Immer konnte es sein, dass die Muschel zerbrach, und deshalb suchte sie sich eine kleine Kiste, um die Muschel stets vor zufälligem Schaden zu schützen.

Nun war die Muschel so schön und in der Schachtel so herrlich anzusehen, so dass viele Menschen kamen, um das kleine Wunder zu bestaunen.

Eines Tages kam ein anderes Mädchen, sie kam aus einem Land, wo keine Wasser sie begleiteten. Sie hatte jedoch gelernt, alle Steinwege zu gehen, auf kleinen Steinen, auf grossen Steinen, um Steine herum, die den Weg versperren.

Sie begann auch Steine zu sammeln: bizarre, kantige und auch hässliche.

Bald hatte sie eine grosse Sammlung.

Sie wollte, dass ihre Steine auch so beachtet werden wie die schöne Muschel, von der sie gehört hatte ... Sie putzte und putzte an ihnen herum, aber sie blieben so, wie sie nun waren. So war sie aber viel beschäftigt und sie konnte von ihrem schweren Handwerk täglich erzählen.

Dann sah sie plötzlich die schöne, strahlende Muschel, ihre harmonischen Windungen, ihre Schattierungen, ihre ebenmässige Form.

Sie ahnte die Mühe des Wassermädchens, die in dieser Muschel verwoben war. Das passte ihr nicht. Und nun begann sie, von allen Seiten mit all ihren Steinen auf die Muschel zu werfen, und auch das schützende Kästchen musste zerstört werden.

Bald merkte sie auch, dass die Muschel so schön war, weil das Wassermädchen sie stets säuberte. Und alsbald begann sie, mit ihren Steinen auch nach dem Wassermädchen zu werfen, damit sie ihre Muschel nicht mehr pflegen kann und diese bald so stumpf werden würde wie ihre Steine und dann die Menschen ihre Steine für Muscheln halten würden.

Doch gibt es eine Moral in der Geschicht: Muscheln nützen Steinewerfern nichts ...

\section{Ausstellung und Lesung von Harriet Keller-Wossidlo}

In der «Galerie am Bach» an der Hauptstrasse 90 im solothurnischen Erlinsbach sind vom 30. November bis 21. Dezember 2008 Bilder von Harriet Keller-Wossidlo sowie Werke einer Reihe weiterer Künstler zu sehen. Die Vernissage, bei der die Künstler anwesend sein werden, findet am Sonntag, 30. November, ab 11 Uhr statt.

Am Sonntag, 7. Dezember 2008, liest Harriet Keller-Wossidlo am selben Ort ab 11 Uhr im Rahmen des «Galerie-Frühstücks» aus ihrem neuen Kunstbuch «Gelesene Bilder». Der Eintritt ist frei. 